\title{
Psychiatric Nurses' Anxiety and Cognition in Managing Psychiatric Patients' Aggression
}

\author{
Shing-Chia Chen, Hai-Gwo Hwu, and Reg Arthur Williams
}

\begin{abstract}
This study explored the anxiety, attitudes, and cognition of the need for aggression management among Taiwanese psychiatric nurses caring for psychiatric patients. Data were collected with self-report questionnaires from 180 psychiatric nurses in the acute wards of three large psychiatric centers in Taiwan. Results showed increased threat of cognitive appraisal of aggression, increased trait anxiety, and decreased positive attitudes toward aggression predicted higher levels of state anxiety. There were significantly higher levels of state anxiety among psychiatric nurses when patients exhibited verbal and physical aggression rather than just physical aggression. An important outcome of this study is the added understanding of cognitive appraisal, trait anxiety, and attitudes, that influence the anxiety of psychiatric nurses.
\end{abstract}

(C) 2005 Elsevier Inc. All rights reserved.

$\mathbf{T}$ HE POTENTIAL VIOLENCE of psychiatric patients is a significant issue in psychiatric wards. The prevalence of violence among psychiatric inpatients ranges from $6.1 \%$ to $35 \%$ (Grassi, Peron, Marangoni, Zanchi, \& Vanni, 2001; Haller \& Deluty, 1988; Lee, Fan, \& Tsai, 1987; Ruesch, Miserez, \& Hell, 2003; Steinert, Wiebe, \& Gebhardt, 1999; Walker \& Seifert, 1994). An American study reported 2.54 assaults per bed yearly among psychiatric wards, compared with 0.73 in nonpsychiatric wards (Reid, Bollinger, \& Edwards, 1985). Patients with acute psychosis are often characterized by less insight and less tolerance of stress (Levy, Salagnik, Rabinowitz, \& Neumann, 1989). These affect their judgment and anger reaction to reality. Their behavior can cause anxiety in staff members who care for them, although the proportion of violent crimes committed by people suffering from severe mental disorders is small (Angermeyer, 2000).

This study explored the level and the attribution factors of Taiwanese psychiatric nurses' state anxiety in managing aggression. Psychiatric nurses' cognitive appraisal about the threat of aggression, trait anxiety, and attitudes toward aggression were examined for effects on state anxiety when they managed patients' aggressive behaviors.

\section{LITERATURE REVIEW}

Psychiatric Nurses' Risk and Anxiety in Managing Aggression

The prevalence of violent injury upon nursing staff members is alarmingly high across nursing

From the Department of Nursing, National Taiwan University College of Medicine and National Taiwan University Hospital, Taipei, Taiwan; Department of Psychiatry, National Taiwan University College of Medicine, and National Taiwan University Hospital, Taipei, Taiwan; and School of Nursing and Psychiatry, Medical School, University of Michigan, Ann Arbor, MI. Address reprint requests to Shing-Chia Chen, RPN, PhD Candidate, Senior Lecturer, School of Nursing, College of Medicine, National Taiwan University, 1 JenAi Road, Sec. 1, Taipei 100, Taiwan, ROC.

E-mail address: scchen@ha.mc.ntu.edu.tw

(C) 2005 Elsevier Inc. All rights reserved.

0883-9417/1801-0005\$30.00/0

doi:10.1016/j.apnu.2005.04.006 
employment categories (Love \& Hunter, 1996). An international study showed that most of the 999 nurse staff members $(75 \%)$ who participated in the study reported being physically assaulted at least once during their career (Poster, 1996). Hou and Liao (1983) found that 18 of 19 Taiwanese nurses $(94.7 \%)$ working in acute psychiatric wards had to use aggression management or had suffered from direct aggressive behaviors from inpatients and that $95 \%$ of them were physically injured. In addition, Chen (1997) found that Taiwanese psychiatric nurses were at the highest risk $(26.3 \%)$ of physical aggression from inpatients whereas psychiatrists were at the second highest risk (13.2\%) among psychiatric staff members in a 5 -month period of prospective data collection in an acute psychiatric ward. Poster (1996) argued that experiencing aggression or violence from patients is an expected occupational hazard of multinational psychiatric nursing staff members across the United Sates, Canada, United Kingdom, and South Africa. It is natural for psychiatric nurses to experience anxiety in managing aggressive behaviors, and the lack of safety may be the key source to their anxiety (Poster, 1996). In addition, role conflict and decision dilemma adds to anxiety during the management process (Dawson, Johnston, Kehiayan, Kyanko, \& Martinez, 1988). As an example, an ethnographic study in Canada concluded that nurses perceived the use of restraint with tension between the need to maintain the safety of patients and staff and to meet the welcome option of restraint (Marangos-Frost \& Wells, 2000).

Attitudes, Cognitive Appraisal, and State Anxiety in Managing Aggression

Experiencing patients' aggression is an integral part of the work of psychiatric nurses. Yet, most psychiatric nurses $(62 \%)$ reported that they felt safe about patients' aggression in their work environment most of the time (Poster, 1996). It seems that psychiatric nurses experience state anxiety in managing patients' aggression but may hold positive attitudes. Nyamathi and Kashiwabara (1988) reported that psychiatric nurses' cognitive appraisal of the aggression risk may be a critical factor but that anxiety also influences their thinking during the aggression management process. Anxiety can create a behavior pattern in managing patients' aggression in the clinical setting (Vasey \& MacLeod, 2001). Psychiatric nurses' anxiety and cognition in managing psychiatric patients' aggression are important issues for clinical practice, but these issues still lack empirical clarity (Berod, Klay, Santos-Eggimann, \& Paccaud, 2000; O'Connor, Connery, \& Cheyne, 2000; Poorman, 1988).

Personal Trait, Characteristics, and State Anxiety in Managing Aggression

According to Beck (1985), the degree of behavioral arousal and subjective anxiety is proportional to a person's subjective estimate of danger. An individual with a high anxious trait evaluates a relatively innocuous stimulus as having a higher subjective threat compared with one who has a low anxious trait (Mogg \& Bradley, 1998). In addition, the degree of estimated danger (i.e., the risk of injury) and consequent fear reaction is proportional to a person's estimate of both the severity of the potential injury and the probability of it occurring. For psychiatric nurses, Poyner and Warne (1986) mentioned that the basic personal characteristics (e.g., age, sex), along with other certain personal characteristics (e.g., less experience), and psychological attributes (personality and belief toward others) would contribute to the stress response of anxiety. Therefore, psychiatric nurses' personal background, trait anxiety, attitudes toward psychiatric patients' aggression, and cognitive appraisal of the threatened level for patients' characteristics and aggressive incidents should be included as crucial attributing factors of psychiatric nurses' state anxiety in managing psychiatric patients' aggression.

\section{METHOD}

This study was a retrospective survey for psychiatric nurses to report their anxiety in managing patients' aggressive behaviors. Patients' aggressive behavior was defined as "any form of threatened behavior, including verbal or physical acts, to cause harm to a person or damage to an object." We specified psychiatric nurses' anxiety experiences in the situation of managing psychiatric patients' aggressive behaviors. The management of aggressive incident was limited to the nurses' real experience in managing psychiatric patients' aggressive behaviors and perceived as the most threatening one during their career, without limiting to the occurrence time. 


\section{Subjects}

Psychiatric nurses who had experienced the management of patients' aggressive behaviors were recruited and volunteered to participate in this study after they were fully informed about its purpose. There were 214 questionnaires distributed and 209 of them were completed and returned. The response rate was $97.7 \%$. We excluded 29 questionnaires from nurses who had no experience in managing patients' aggressive behavior. Finally, a total of 180 questionnaires indicated experience with aggressive behaviors; therefore, they were included in the analysis.

Subjects' ages ranged from 20 to 51 years and the mean age was 29.4 years $(S D=5.9$ years $)$. Most of them were single and women, more than half of them holding a diploma in nursing. Almost half of them were of eastern religious affiliation and more than one third had no religion affiliation. Most of the nurses had psychiatric nursing experiences before they were employed with their respective hospital units and their experiences were in acute psychiatric units (see Table 1).

\section{Measures}

\section{State-Trait Anxiety Inventory}

The Chinese version of the State-Trait Anxiety Inventory, which was developed by Spielberger, Gorsuch, and Lushene (1970), was used, including the Trait Anxiety Inventory (TAI) and the State Anxiety Inventory (SAI), with satisfactory reliability (Chung, 1982). The TAI and the SAI are 20-item summated rating scales of a 4-point Likert type that assess the intensity of anxiety. Higher scores indicate higher anxiety. In this study, the 2-week test-retest reliability of the TAI from one pilot study samples of a semi-locked ward was .88. The internal consistencies (Cronbach coefficient $\alpha$ ) of the TAI and the SAI were .89 and .96 , respectively.

\section{Cognition of Aggression Management Scale}

The Chinese version of the Cognition of Aggression Management Scale (CAMS) was designed based on the literature reviewed and clinical interviews (Chen, 1997). It is an 18 -item summated rating scale. Each item is of a 5-point Likert type from totally none to extremely high. The CAMS was used to assess nurses' cognitive appraisal of the threatened level in managing their most threatening
Table 1. Demographic Data of 180 Psychiatric Nurses

\begin{tabular}{|c|c|c|c|c|}
\hline Demographics & $M(S D)$ & Range & $n$ & $\%$ \\
\hline \multirow[t]{3}{*}{ Age } & 29.4 years $(5.9)$ & $\begin{array}{c}20-29 \\
\text { years }\end{array}$ & 110 & 61.1 \\
\hline & & $\begin{array}{c}30-39 \\
\text { years }\end{array}$ & 51 & 28.3 \\
\hline & & $\begin{array}{l}40-51 \\
\text { years }\end{array}$ & 16 & 8.9 \\
\hline Missing & & & 3 & 1.7 \\
\hline \multicolumn{5}{|l|}{ Sex } \\
\hline Male & & & 10 & 5.6 \\
\hline Female & & & 168 & 93.3 \\
\hline Missing & & & 2 & 1.1 \\
\hline \multicolumn{5}{|l|}{ Marital status } \\
\hline Single & & & 116 & 64.4 \\
\hline Married & & & 64 & 35.6 \\
\hline \multicolumn{5}{|l|}{ Religious affiliation } \\
\hline None & & & 70 & 38.9 \\
\hline Eastern & & & 80 & 44.4 \\
\hline Western & & & 21 & 11.7 \\
\hline Others & & & 8 & 4.4 \\
\hline Missing & & & 1 & 0.6 \\
\hline \multicolumn{5}{|c|}{ Nursing education background } \\
\hline Certificate & & & 4 & 2.2 \\
\hline Diploma & & & 101 & 56.1 \\
\hline Bachelor's degree & & & 73 & 40.6 \\
\hline Master's degree & & & 2 & 1.1 \\
\hline \multicolumn{5}{|c|}{ Psychiatric nursing experience } \\
\hline Yes & & & 175 & 97.2 \\
\hline No & & & 4 & 2.2 \\
\hline Missing & & & 1 & 0.6 \\
\hline \multicolumn{5}{|c|}{ Types of psychiatric nursing experience } \\
\hline $\begin{array}{l}\text { Outpatient } \\
\text { department }\end{array}$ & 1.2 months (4.7) & & 15 & 8.3 \\
\hline Day care unit & 0.7 months (3.3) & & 10 & 5.6 \\
\hline Chronic unit & 11.1 months (19.4) & & 63 & 35.0 \\
\hline Acute unit & 39.8 months (31.7) & & 170 & 94.4 \\
\hline ICU/ES & 1.8 months (7.3) & & 13 & 7.2 \\
\hline Substance unit & 2.2 months (13.4) & & 10 & 5.6 \\
\hline Neurotic unit & 2.6 months (13.9) & & 12 & 6.7 \\
\hline $\begin{array}{l}\text { Others } \\
\text { (geriatric unit, } \\
\text { halfway house) }\end{array}$ & & & 5 & 2.8 \\
\hline
\end{tabular}

aggressive incidents. Items include the situation itself, intention of the patient offenders, and the process of management. The CAMS scores range from 0 to 80 . Higher scores indicate higher threatened levels. Content validity of the CAMS was determined by a panel of expert judges: two psychiatrists and four psychiatric nurse professionals. After completing the analysis of corrected item-total correlation, two unrelated items were deleted; therefore, the scale in this study had 16 items. The internal consistency of CAMS was .71 in this study. 


\section{Attitude Scale}

The Chinese version of the Attitude Scale (AS), which was originally developed by Poster and Ryan (1989) and later modified by Collins (1994), was used to measure nurses' attitudes toward psychiatric patients' aggression (Cheng, Tsai, Chan, Liao, \& Chang, 1999). The AS is a 25 -item summated rating scale of a 5-point Likert type from totally agree to totally disagree that assesses the following: attitudes toward the statements of prevention, patients' motivation and responsibility, nurses' needs for training and ability in managing aggressive behaviors, and environmental factors of aggressive behaviors. The AS scores range from 25 to 125 . Higher scores indicate a more positive attitude. After completing the analysis of corrected item-total correlation, three unrelated items were deleted. The test-retest reliability from the pilot study samples of a semi-locked ward of the AS was .59. The internal consistency was .83 in this study.

\section{Aggressive Incident Items}

These were designed to understand the most threatening aggressive incident encountered by the nurses among their past management experiences for psychiatric patients' aggressive behaviors. The items included the psychiatric patient offender's sex, age, and psychiatric diagnosis; the occurrence time, the targets, and types of aggression; and the methods of management.

\section{Subjects' Basic Data Items}

These items included age, sex, marital status, religion, education level, and previous psychiatric nursing experience.

\section{Procedures and Data Collection}

Two pilot studies were conducted with 24 psychiatric nurses in two acute psychiatric wards, one was an open ward $(n=11)$ and the other was a semilocked ward $(n=13)$, of a university teaching hospital in Taiwan. Their response data were obtained to modify the study questionnaires and procedures of administration. The nurses of the open ward had very low exposure rates and had rare events of remote memory in their real experience of aggression management.

Thus, in the formal study, data were collected on all acute semi-locked psychiatric wards in three large psychiatric centers. Nurses were invited to answer the questionnaires anonymously on a voluntary basis. The order of the tools was intentionally arranged. After general items (basic data, AS, and TAI), the nurses were then instructed to answer specific items of their most threatening aggressive incidents, the CAMS, and then the SAI. The nurses were instructed to think about past patients who exhibited aggressive behavior to identify how they managed the situation. All the nurses were instructed to return the completed questionnaires in a provided sealed envelope placed in a large envelope for the researcher.

\section{Data Analysis}

Descriptive statistics were used to describe the nurses, patient offenders, and aggressive incidents. Pearson's correlation, $t$ test, and analysis of variance (ANOVA) with Scheffe's test were used to test bivariate and multivariate relationships. Stepwise linear regression with forward entry was used for the analysis of SAI (dependent variable) as a function of all significantly attributing factors. If the measurement level of a significant attributing factor was categorical, such as the type of aggression, it was judged by severity to transform to a dummy variable for analysis. Residual analysis was conducted to determine any violation of using multiple regression. No violations were noted. The statistical analyses were carried out using the program SPSS 10.0 for Windows. An $\alpha$ level of .05 (two tailed and pair wised) was set a priori.

\section{RESULTS}

\section{Characteristics of the Most Threatening Aggression}

Based on the nurses' data, most of the patient offenders were men, more than $40 \%$ were young adults or were middle-aged adults, and more than half were diagnosed with schizophrenia (see Table 2). Exclusive of missing data (5.6\%), the types of aggression by order were verbal plus physical $(n=99,55.0 \%)$, only physical $(n=49$, $27.2 \%)$, and only verbal $(n=31,17.2 \%)$. The order of the priority of the management method for the aggressive behaviors was the use of an isolation room $(n=143,79.4 \%)$, medical injection $(n=137,76.1 \%)$, physical restraints $(n=135$, 
Table 2. Basic Data of the Patient Offenders Described by 180 Psychiatric Nurses

\begin{tabular}{lrr}
\hline \multicolumn{1}{c}{ Items } & $n$ & $\%$ \\
\hline Sex & 130 & 72.2 \\
Male & 48 & 26.7 \\
Female & 2 & 1.1 \\
Missing & & \\
Age & 14 & 7.8 \\
Adolescent & 81 & 45.0 \\
Young adult & 77 & 42.8 \\
Middle adult & 8 & 4.4 \\
Elder & & \\
Diagnosis & 92 & 51.1 \\
Schizophrenia & 24 & 13.3 \\
Substance abuse/dependence & 23 & 12.8 \\
Manic episode & 18 & 10.0 \\
Comobility of two diagnoses* & 7 & 3.9 \\
Organic mental disorder & 6 & 3.3 \\
Delusional disorder & 5 & 2.8 \\
Personality disorder & 5 & 2.8 \\
Others & & \\
\hline
\end{tabular}

*Combination of schizophrenia, mania, mental retardation, personality disorder, delusional disorder, adjustment disorder, or substance abuse/dependence.

$75.0 \%)$, verbal de-escalation $(n=114,63.3 \%)$, isolation of each other $(n=72,40.0 \%)$, and after care $(n=8,4.4 \%)$. Minimal aggression dismissed without any management $(n=5,2.8 \%)$ included situations wherein a patient offender or victim escaped or a patient offender was immediately discharged from the unit against the treatment. Other management types $(n=2,1.1 \%)$ that could not be categorized included calling for police help without details. Nearly half of the nurses $(48.3 \%)$ indicated that they were the targets of aggression and the data showed that $30.0 \%$ were other patients. The range in the time of occurrence of the aggressive incident was from 1 day to 15 years (range, $1-5,475$ days, $M=452$ days, $S D=799$ days). It was interesting to note that the psychiatric nurses seldom missed the response to items which related to the background data of the aggressive patients and incidents.

\section{State Anxiety and Attribution Factors in Managing Aggression}

In bivariate correlation analysis, nurses' age was significantly inversely related to the SAI score $(r=-.16, P=.037)$ and the TAI score $(r=-.24$, $P=.001)$ and positively related to the AS score $(r=.21, P=.005)$, but there was no significant correlation with the CAMS score.

Table 3. Bivariate Analysis for the Items of Most Threatening Aggressive Incidents That Were Significant on State Anxiety (SAI), Trait Anxiety (TAI), Attitude (AS), and Cognition of Aggression Management (CAMS)

\begin{tabular}{|c|c|c|c|c|c|c|c|c|}
\hline \multirow[b]{2}{*}{ Items } & \multicolumn{2}{|c|}{ SAl } & \multicolumn{2}{|c|}{ CAMS } & \multicolumn{2}{|c|}{ TAl } & \multicolumn{2}{|c|}{ AS } \\
\hline & M & SD & M & $S D$ & $M$ & $S D$ & M & $S D$ \\
\hline Total & 42.0 & 13.2 & 39.2 & 6.5 & 42.9 & 4.2 & 70.2 & 5.1 \\
\hline \multicolumn{9}{|l|}{ Type of aggression } \\
\hline Verbal $(n=31)$ & 42.3 & 13.9 & $34.0 *$ & 8.0 & 43.1 & 6.7 & 74.1 & 7.4 \\
\hline Physical $(n=49)$ & $37.6 \dagger$ & 12.2 & 36.3 & 7.4 & 40.4 & 7.7 & 76.5 & 6.5 \\
\hline Verbal plus physical $(n=98)$ & $44.2 \dagger$ & 13.0 & $37.8 *$ & 5.7 & 41.0 & 6.5 & 75.5 & 5.8 \\
\hline \multicolumn{9}{|l|}{ Nurses as targets of aggression } \\
\hline No $(n=92)$ & 41.0 & 11.9 & $35.5 \ddagger$ & 5.8 & 41.0 & 7.1 & 75.4 & 6.3 \\
\hline Yes $(n=87)$ & 43.0 & 14.4 & $38.1 \ddagger$ & 7.5 & 41.4 & 6.8 & 76.0 & 6.4 \\
\hline \multicolumn{9}{|c|}{ Other patients as targets of aggression } \\
\hline No $(n=125)$ & 42.6 & 13.5 & $37.6 \S$ & 7.2 & 41.5 & 6.9 & 75.6 & 6.3 \\
\hline Yes $(n=54)$ & 40.6 & 12.5 & $35.0 \S$ & 5.4 & 40.5 & 7.1 & 75.8 & 6.4 \\
\hline \multicolumn{9}{|c|}{ Medical injection as the method of management } \\
\hline No $(n=43)$ & 43.3 & 14.4 & $34.8 \|$ & 8.0 & 43.1 & 7.4 & 75.1 & 7.5 \\
\hline Yes $(n=136)$ & 41.6 & 12.8 & $37.4 \|$ & 6.2 & 40.6 & 6.6 & 75.8 & 5.9 \\
\hline \multicolumn{9}{|c|}{ Physical restraint as the method of management } \\
\hline No $(n=45)$ & 41.4 & 14.0 & 34.29 & 7.9 & 43.6\# & 7.1 & 74.9 & 8.2 \\
\hline Yes $(n=134)$ & 42.2 & 12.9 & 37.79 & 6.1 & 40.4\# & 6.7 & 75.9 & 5.6 \\
\hline
\end{tabular}

*Type of aggression with the CAMS: $F(177)=4.0, P=.020$; Scheffe's test: $t=-3.8, P=.024$.

$\dagger$ Type of aggression with the SAI: $F(177)=4.2, P=.016$; Scheffe's test: $t=-6.6, P=.016$.

$\ddagger$ Nurses themselves as the target of aggression with the CAMS: $t(161.8)=-2.6, P=.010$.

$\S$ Other patients as the target of aggression with the CAMS: $t(131.7)=2.7, P=.009$.

$\|$ Medical injection management with the CAMS: $t(58.9)=-2.0, P=.050$.

ๆ Physical restraint management with the CAMS: $t(62.6)=-2.7, P=.010$

\#Physical restraint management with the TAl: $t(177)=2.7, P=.007$. 
Table 4. Correlations Between Attitude (AS), Trait Anxiety (TAI), State Anxiety (SAI), and Cognition of Aggression Management (CAMS)

\begin{tabular}{lcrr}
\hline & TAI & CAMS & SAI \\
\hline AS & $-.39 *$ & -.10 & $-.30 *$ \\
TAI & & -.06 & $.29 *$ \\
CAMS & & $.40 *$ \\
\hline
\end{tabular}

Note. $* P \leq .01$ (two tailed).

Table 3 shows that the items of most threatening aggressive incidents significantly attributed to the SAI, CAMS, TAI, and AS using $t$ test or ANOVA with Scheffe's test. Type of aggression was verbal plus physical aggression, which was significantly higher than only verbal aggression in the SAI; and verbal plus physical aggression was significantly higher than verbal aggression in the CAMS. Target of aggression either toward nurses themselves or toward other patients was higher in the CAMS. The most frequent methods of management for aggression were isolation $(n=143$, $79.4 \%)$, medical injection $(n=137,76.1 \%)$, and physical restraints $(n=135,75.0 \%)$. These factors, however, were not significantly related to the SAI. Results showed that the nurses with lower TAI scores used physical restraints more frequently. Exclusive of the types of aggression, the factors attributed to the CAMS had no significant correlation with the SAI.

Higher TAI significantly related to higher SAI. The AS had a significantly inverse correlation with the TAI and SAI. The CAMS was a unique attribution variable with SAI but was not significantly related with the AS and TAI (see Table 4).

In further multivariate analysis, results showed that an increased SAI was predicted by an increased CAMS, an increased TAI, and a decreased AS, with $31 \%$ of the variance explained by these predictor variables (see Table 5). Nurses' age and type of aggression did not significantly predict the SAI in this regression model.

\section{DISCUSSION}

The results of this study, which are consistent with those of previous research, showed that patients who exhibited aggression were likely to be men, younger (Ruesch et al, 2003), and with a diagnosis of schizophrenia (Grassi et al., 2001; Saverimuttu \& Lowe, 2000; Tam, Engelsmann, \& Fugere, 1996). The nurses indicated that their most frequent methods of management of aggression were use of the isolation room, medications, and physical restraints. This may be the product of the nurses' recall of the most threatening aggression by patients. Psychiatric nurses were at the highest risk as targets of aggression, the percentage of which is consistent with that of the finding of Blair and New (1992) that half of psychiatric staff members had been attacked at some point during their work career.

In general, the need for education and knowledge of aggression, the skills for aggression management, and psychological support are necessary for nurses to cope with aggressive incidents. Specifically, these needs for education and knowledge can be stressed to reduce the anxiety of psychiatric nurses (Poster \& Ryan, 1989). The ways of counterbalancing stress adaptation and support in patient settings are to reduce psychiatric nurses' state anxiety.

Stemming from the above inferences, it is argued that it is healthier if psychiatric nurses with low cognitive appraisal have low state anxiety. Yet, an appropriate level of anxiety may improve performance by increasing effort, but performance may be impaired on high anxiety levels because the increased effort may not be an adequate compensatory mechanism (Lister, 1991). Thus, the understanding of psychiatric nurses' appropriate level of anxiety in managing psychiatric patients' aggression needs to be further explored.

Cognitive factors play an important role and often a critical one in human behavior and emotional

Table 5. Stepwise Multiple Regression Analysis of Nurses' State Anxiety Contributed by Cognition of Aggression Management (CAMS), Attitude (AS), and Trait Anxiety (TAI)

\begin{tabular}{lccccccc}
\hline Step & Variable & Multiple $R$ & $R^{2}$ & $R^{2}$ change & $\beta$ & $F$ & Significant $F$ change \\
\hline 1 & CAMS & .44 & .19 & .19 & .44 & 40.12 & $<.001$ \\
2 & TAI & .54 & .29 & .10 & .25 & 34.59 & $<.001$ \\
3 & AS & .56 & .31 & .02 & -.15 & 25.14 & $<.001$ \\
\hline
\end{tabular}

NOTE. $n=172$ 
response such as facing aggressive behavior (Eron, 1994). Quinsey and Cyr (1986) reported that clinicians' ratings of the treatability of offenders were inversely related to their perceived danger. Our study showed that cognitive appraisal is the most important immediate determinant and that the hypothesis regarding the positive correlation with psychiatric nurses' state anxiety in managing aggression was supported by the data. The mean score of the CAMS was lower than the 50th percentile score, which may reflect that the perceived risk levels of patients' aggressive incidents in acute psychiatric wards usually are not severe (Chen, 1997). In addition, the CAMS was not correlated with the TAI and AS. The different attribution may be due to the situational interactive attribute of the CAMS, which is related to a personal judgment of the aggressive situation, comparing it with the personal long-lasting characteristics of the TAI and AS.

From a cognitive-motivational viewpoint for analysis of anxiety, Mogg and Bradley (1998) suggested that stimuli are judged to be significantly threatening and that the vulnerability to anxiety stems mainly from a lower threshold for appraising threat. The result of our study showed that the most threatening aggressive incident might be a greater stimulus that affects psychiatric nursing staff members' judgment, adjusts their cognitive appraisal, and plays an important role in provoking their state anxiety. The situation becomes more complicated when psychiatric nurses are not only caregivers but also the targets of the aggression. Psychiatric nurses need personal growth and support during the management of psychiatric patients' aggression to prevent cognitive bias (Beck, 1985; Vasey \& Macleod, 2001) when performing their roles. The alternatives to reduce the cognitive bias could include training to enhance the comprehension of the risk factors and ways to intervene when patients express anger or aggressive behavior.

Inversely, from the aspect of problem solving and the effect of anxiety on cognitive performance (Nyamathi \& Kashiwabara, 1988; Poorman, 1988), we should consider further outcome variables that are affected by state anxiety. These may be related to psychiatric nursing staff members' performance in managing patients' aggression. For example, further studies can evaluate the effects of state anxiety on nurses' competency or efficiency in managing aggression.
The TAI is an important attributing factor for the SAI, especially because there was a tendency with higher trait anxiety among psychiatric nurses than among nonpsychiatric nurses (De Lucio et al., 2000). Based on the trait-state theory of anxiety (Spielberger et al., 1970), persons with a higher TAI perceived more intense SAI when they were under stressful conditions. Situational state anxiety may be transformed into personal stable trait anxiety if a person's stressful situation lasts for a long period (Spielberger et al, 1970). The result of our study showed that psychiatric nurses' TAI positively related to their SAI in managing patients' aggression and that the $S D$ of the SAI was much greater than that of the TAI. These findings were supported by other studies (Chung \& Long, 1984; Yarcheski, Mahon, \& Yarcheski, 1999).

Psychiatric nurses' attitudes toward psychiatric patients are usually more positive than those of nonpsychiatric nurses because of their involvement in psychiatric working experience and their interest to commit themselves as psychiatric patients' care providers (Chen, 1993; Roman \& Floyd, 1981). Our finding showed that AS was one important attributing factor and was inversely related to SAI. Generally, there were few researchers who have studied the issue of psychiatric nurses' attitudes toward patients' aggression and the results have varied widely (Poster \& Ryan, 1989; Baxter, Hafner, \& Holme, 1992). Collins (1994) did a quasi-experimental study to examine an aggression prevention and management program, which had positive effects on the psychiatric nurses', assistants', and students' attitudes. They became less anxious after the program in managing patients' aggression. Their confidence became greater in prediction and management of aggression (Collins, 1994), which is consistent with our findings.

The patterns of psychiatric nurses' attitudes toward patients' aggression are better understood as the basis for continuous education to promote their role and function in psychiatric patients care. It would be better to debunk myths toward patients' aggression for promoting attitudes, such as that "the patient with a mental illness who strikes out is viewed as out of control," "good psychiatric nurses' job is to help patients to regain control to ensure a safe environment," "aggression occurs when staff are inconsistent or are in conflict," and "the clinician who is afraid is most often the victim of assault" (Morrison, 1993, pp. 330, 332, and 333). 
Psychiatric nurses need to recognize the interactional dynamics of violence as well as possess suitable assessment and decision-making skills for preventing and managing aggression (Morrison, 1992; O'Brien \& Cole, 2003). The development of continuing professionals' attitudes in the therapeutic milieu toward psychiatric patients and their aggressive behavior is recommended.

One limitation of this study is its retrospective design, which means that our findings are correlative and do not provide a basis for drawing conclusions about the causality for state anxiety when psychiatric nurses managed the aggressive behaviors of the patients. The data of cognition and anxiety toward aggression management were assessed using self-reports, which are subject to the nursing staff members' memory and willingness to disclose sensitive information. Despite the unavoidable limitations of this research design, the study results did support other research findings and provided empirical data to the literature on aggression and psychiatric nurses' state anxiety and the potential attributing factors. These data can be of practical value and will be a reference for further prospective study designs.

\section{CONCLUSION}

This study, other than supporting previous research reports, examined a wider range of variables for the conceptualization of psychiatric nurses' state anxiety in managing patients' aggression. The major attributing factors are their cognitive appraisal, trait anxiety, and attitudes toward psychiatric patients' aggression. The results differentiated the major attributing factors to two attributes: situational interactive attribute, such as their cognitive appraisal of the threatened level during their managing aggression, and long-lasting stable attribute, such as psychiatric nurses' individual trait anxiety and attitudes toward aggression. From psychoeducation and affective-behavioral domains, learning could make long-term stable attributes of an individual more positive or healthy. Situational interactive attributes, contributing the most variance to the psychiatric nurses' state anxiety in managing patients' aggressive behaviors, need environmental support and continuous education for their critical judgment and effective management. We suggest that the approaches would lower psychiatric nurses' state anxiety but keep it at an appropriate level in managing psychiatric patients' aggression. Regarding which level of psychiatric nurses' state anxiety is optimal, it was not answered by this study but warrants further study.

\section{ACKNOWLEDGMENT}

This study was supported by the National Taiwan University Hospital, Taiwan, ROC (S90-2500-87). We thank all the nurses who participated in the study and the psychiatric center officers; six expert juries for content validity of the scales; Myrna Buiser and Hey-Jen Chen for their suggestions; and Chi-Fan Chang and Ming-I Lin for their assistance.

\section{REFERENCES}

Angermeyer, M. C. (2000). Schizophrenia and violence. Acta Psychiatrica Scandinavica Supplementum, 102(407), 63-67.

Baxter, E., Hafner, R. J., \& Holme, G. (1992). Assaults by patients: The experience and attitudes of psychiatric hospital nurses. Australian and New Zealand Journal of Psychiatry, 26(4), 567-573.

Beck, A. T. (1985). The cognitive model of threat reactions. In A. T. Beck, \& G. Emery (Eds.), Anxiety disorders and phobias: A cognitive perspective (pp. 37-53). New York: Basic Book's.

Berod, A. C., Klay, M., Santos-Eggimann, B., \& Paccaud, F. (2000). Anxiety, depressive, or cognitive disorders in rehabilitation patients: Effect on length of stay. American Journal of Physical Medicine \& Rehabilitation, 79(3), 266-273.

Blair, D. T., \& New, S. A. (1992). Patient violence in psychiatric settings: Risk identification and treatment as provocation. In S. A. Smoyak, \& D. T. Blair (Eds.), Violence and abuse (pp. 36-53). New Jersey: Slack.

Chen, S. C. (1993). The effects of nurses' working experience at psychiatric department on their attitudes toward psychotic patients. Public Health, 20(1), 70-82.

Chen, S. C. (1997). Study of patients' violent behavior in an acute psychiatric ward. Journal of Nursing Research, 5(2), 195-205

Cheng, S. L., Tsai, S. L., Chan, C. H., Liao, R. L., \& Chang, M. (1999). The effects of the violence management program on psychiatric nurses' knowledge of patient violence, attitudes toward violence, and management of violent behavior. Journal of Nursing Research, 7(5), 408-422.

Chung, S. K. (1982). Introduction of modified State Anxiety Inventory. Ts'e Yen Yu Fu Tao, 10, 789-790.

Chung, S. K., \& Long, C. F. (1984). A study of the revised State-Trait Anxiety Inventory. Psychological Testing, 31(1), 27-36.

Collins, J. (1994). Nurses' attitudes towards aggressive behaviour, following attendance at 'The Prevention and Management of Aggressive Behaviour Programme'. Journal of Advanced Nursing, 20(1), 117-131.

Dawson, J., Johnston, M., Kehiayan, N., Kyanko, S., \& Martinez, R. (1988). Response to patient assault. A peer 
support program for nurses. Journal of Psychosocial Nursing and Mental Health Services, 26(2), 8-11, 15.

De Lucio, L. G., Garcia Lopez, F. J., Marin Lopez, M. T., Hesse, B. M., \& Caamano Vaz, M. D. (2000). Training programme in techniques of self-control and communication skills to improve nurses' relationships with relatives of seriously ill patients: A randomized controlled study. Journal of Advance Nursing, 32(2), 425-431.

Eron, L. D. (1994). Theories of aggression: From drives to cognitions. In L. R. Huesmann (Ed.), Aggressive behavior: Current perspective (pp. 3-11). New York: Plenum.

Grassi, L., Peron, L., Marangoni, C., Zanchi, P., \& Vanni, A. (2001). Characteristics of violent behaviour in acute psychiatric in-patients: A 5-year Italian study. Acta Psychiatrica Scandinavica, 104(4), 273-279.

Haller, R. M., \& Deluty, R. H. (1988). Assaults on staff by psychiatric in-patients. A critical review. British Journal of Psychiatry, 152(1), 174-179.

Hou, H. L., \& Liao, C. A. (1993). Developing a continuous quality improvement project: Monitoring damage rate of violence in psychiatric wards. Veterans General Hospital Nursing, 10(4), 383-392.

Lee, Y. C., Fan, S. H., \& Tsai, G. C. (1987). Assaultive behaviors among psychiatric inpatients-A retrospective study. Chung Huai Hsueh Tsa Chih-Chinese Medical Journal, 39(5), 323-332.

Levy, A., Salagnik, I., Rabinowitz, S., \& Neumann, M. (1989). The dangerous psychiatric patient: Part I. Epidemiology, etiology, prediction. Medicine and Law, 8(2), 131-136.

Lister, R. G. (1991). Anxiety and cognition. In M. Briley, \& S. E. File (Eds.), New concepts in anxiety (pp. 407-417). London: The Macmillan press Ltd.

Love, C. C., \& Hunter, M. E. (1996). Violence in public sector psychiatric hospitals. Benchmarking nursing staff injury rates. Journal of Psychosocial Nursing and Mental Health Services, 34(5), 30-34.

Marangos-Frost, S., \& Wells, D. (2000). Psychiatric nurses' thoughts and feelings about restraint use: A decision dilemma. Journal of Advanced Nursing, 31(2), $362-369$.

Mogg, K., \& Bradley, B. P. (1998). A cognitive-motivational analysis of anxiety. Behaviour Research and Therapy, 36(9), 809-848.

Morrison, E. F. (1992). A coercive interactional style as an antecedent to aggression in psychiatric patients. Research in Nursing and Health, 15, 421-431.

Morrison, E. F. (1993). Toward a better understanding of violence in psychiatric settings: Debunking the myths. Archives of Psychiatric Nursing, 7(6), 328-335.

Nyamathi, A., \& Kashiwabara, A. (1988). Preoperative anxiety: Its affect on cognitive thinking. AORN Journal, 47(1), $164-170$.

O’Brien, L., \& Cole, R. (2003). Close-observation areas in acute psychiatric units: A literature review. International Journal of Mental Health Nursing, 12(3), 165-176.
O'Connor, R. C., Connery, H., \& Cheyne, W. M. (2000). Hopelessness: The role of depression future directed thinking and cognitive vulnerability. Psychological Health and Medicine, 5(2), 155-161.

Poorman, S. G. (1988). Levels of test anxiety and cognitions of second semester senior level baccalaureate nursing students preparing for licensure exam (p. 154). University of Pittsburgh: Doctoral Dissertation.

Poster, E. C. (1996). A multinational study of psychiatric nursing staffs' beliefs and concerns about work safety and patient assault. Archives of Psychiatric Nursing, 10(6), 365-373.

Poster, E. C., \& Ryan, J. A. (1989). Nurses' attitudes toward physical assaults by patients. Archives of Psychiatric Nursing, 3(6), 315-322.

Poyner, B., \& Warne, C. (1986). Violence to staff: A basis for assessment and prevention. London: HMSO.

Quinsey, V. L., \& Cyr, M. (1986). Perceived dangerousness and the treatability of offenders: The effects of internal versus external attributions of crime and causality. Journal of Interpersonal Violence, 1, 458-471.

Reid, W. H., Bollinger, M. F., \& Edwards, G. (1985). Assaults in hospitals. Bulletin of the American Academy of Psychiatry and the Law, 13(1), 1-4.

Roman, P. M., \& Floyd, H. H. (1981). Social acceptance of psychiatric illness and psychiatric treatment. Social Psychiatry, 16, 21-29.

Ruesch, P., Miserez, B., \& Hell, D. (2003). A risk profile of the aggressive psychiatric inpatient: Can it be identified? Nervenarzt, 74(3), 259-265.

Saverimuttu, A., \& Lowe, T. (2000). Aggressive incidents on a psychiatric intensive care unit. Nursing Standard, 14(35), 33-36.

Spielberger, C. D., Gorsuch, R. L., \& Lushene, R. E. (1970). STAI manual: For the State-Trait Anxiety Inventory (self-evaluation questionnaire). Palo Alto, CA: Consulting Psychologists Press.

Steinert, T., Wiebe, C., \& Gebhardt, R. P. (1999). Aggressive behavior against self and others among first-admission patients with schizophrenia. Psychiatric Services, 50(1), $85-90$.

Tam, E., Engelsmann, F., \& Fugere, R. (1996). Patterns of violent incidents by patients in a general hospital psychiatric facility. Psychiatric Services, 47(1), 86-88.

Vasey, M. W., \& MacLeod, C. (2001). Information-processing factors in childhood anxiety: A review and developmental perspective. In M. W. Vasey, \& M. R. Dadds (Eds.), The developmental psychopathology of anxiety (pp. 253-277). New York: Oxford University Press.

Walker, Z., \& Seifert, R. (1994). Violent incidents in a psychiatric intensive care unit. British Journal of Psychiatry, 164(6), 826-828.

Yarcheski, A., Mahon, N. E., \& Yarcheski, T. J. (1999). An empirical test of alternate theories of anger in early adolescents. Nursing Research, 48(6), 317-323. 